\title{
Cellular imaging of inherited retinal diseases using adaptive optics
}

\author{
Jasdeep S. Gill $\mathbb{1}^{1} \cdot$ Mariya Moosajee $\mathbb{1}^{1,2,3} \cdot$ Adam M. Dubis ${ }^{1,2}$
}

Received: 29 October 2018 / Revised: 25 February 2019 / Accepted: 25 April 2019 / Published online: 4 June 2019

(c) The Author(s) 2019. This article is published with open access

\begin{abstract}
Adaptive optics (AO) is an insightful tool that has been increasingly applied to existing imaging systems for viewing the retina at a cellular level. By correcting for individual optical aberrations, AO offers an improvement in transverse resolution from 10-15 $\mu \mathrm{m}$ to $\sim 2 \mu \mathrm{m}$, enabling assessment of individual retinal cell types. One of the settings in which its utility has been recognised is that of the inherited retinal diseases (IRDs), the genetic and clinical heterogeneity of which warrants better cellular characterisation. In this review, we provide a summary of the basic principles of AO, its integration into multiple retinal imaging modalities and its clinical applications, focusing primarily on IRDs. Furthermore, we present a comprehensive summary of AO-based cellular findings in IRDs according to their associated disease-causing genes.
\end{abstract}

\section{Introduction}

Since its first use in retinal imaging just over 20 years ago [1], adaptive optics (AO) has undergone immense growth in its applications amongst vision scientists and clinicians. This technique has allowed imaging of the living retina at a cellular resolution, leading to revolutionary changes in our understanding of retinal diseases and especially those of monogenic aetiology. In doing so, it has opened exciting avenues for research, monitoring retinal diseases [2-4], and providing new tools for refining diagnosis $[5,6]$.

Adaptive optics was originally a component added to astronomical telescopes to rectify loss of resolution from atmospheric irregularities (wind and moisture) [7]. Its uses have since evolved and have been employed in the fields of microscopy, communication and medicine. In ophthalmic applications, AO is a tool by which monochromatic aberrations present in the optical path of the eye are measured and then compensated. In reference to the eye, the

$\triangle$ Adam M. Dubis

a.dubis@ucl.ac.uk

1 UCL Institute of Ophthalmology, 11-43 Bath Street, London EC1V 9EL, UK

2 NIHR Biomedical Research Centre at Moorfields Eye Hospital NHS Trust and UCL Institute of Ophthalmology, 162 City Road, London EC1V 9PD, UK

3 Great Ormond Street Hospital for Children, Great Ormond Street, London WC1N 3JH, UK measurement and full wavefront correction can improve the transverse optical resolution from $10-15 \mu \mathrm{m}$ to $\sim 2 \mu \mathrm{m}$. This enhanced resolution enables visualisation of numerous retinal cell types including ganglion cells [8, 9], photoreceptors [10-13], and retinal pigment epithelial (RPE) cells $[14,15]$. AO, as a bolt-on technique, has been integrated into multiple existing retinal imaging systems, including flood illumination ophthalmoscopy (FIO) [1, 16], scanning laser ophthalmoscopy (SLO) $[17,18]$ and, most recently, optical coherence tomography (OCT) [19, 20]. Although it is yet to be in widespread clinical use, the advent of AO has truly redefined the possibilities for in vivo retinal imaging and transformed the ophthalmic research space.

One of the most common targets of ophthalmic AO imaging has been in patients with mendelian inherited retinal diseases (IRDs). Patients with IRDs are clinically and genetically heterogeneous; over 250 disease-associated genes have been identified to date, with patients displaying retinal dysfunction, which can be either stationary or progressive, leading to sight loss [21]. Given that the primary cell types affected in IRD patients are photoreceptors and RPE cells, AO-based retinal imaging provides a vital tool for shedding light on cellular pathogenesis, disease progression and its clinical correlation. This is especially true as studies show the detection of microstructural retinal changes prior to functional changes occurring in a patient's vision [22, 23]. Similarly, AO plays a crucial role in sensitively assessing the efficacy of interventions rapidly developing for IRDs, including stem cell, gene replacement and gene modification therapy [24]. In view of the significance of $\mathrm{AO}$ retinal imaging in IRDs, our review 
summarises the cellular changes corresponding with mutation-specific disease, whilst exploring its basic principles, uses and clinical applications.

\section{Basic principles of adaptive optics}

Optical aberrations are deviations of incoming light rays from the ideal path, such that they do not converge into a single point of focus on the retina. Aberrations can largely be attributed to the three optical elements of the eye: the cornea, the pupil and the crystalline lens, however other components (aqueous/vitreous humour and retinal tissue) can also contribute [25]. Whilst the corneal surface contributes to approximately two-thirds of the eye's optical aberrations, the crystalline lens is largely responsible for the remainder through its shape, thickness and cellular alignment. Sitting in-between the cornea and lens, the pupil also affects optical quality by regulating the quantity of light entering and exiting the eye during imaging [26]. Optical aberrations can be classified as being of either low- or highorder. Low-order aberrations, such as defocus and astigmatism, are of greatest magnitude, but corrected with glasses or contact lenses. In contrast, high-order aberrations, such as keratoconus, constitute a small proportion of optical aberrations and have proven more challenging to correct for. Although the effects of many optical aberrations are only detectable with specialist testing [27], others can significantly distort both a patient's vision and their retinal images.

AO-aided imaging compensates for a patient's individual optical aberrations to provide a high-resolution view of the retina. These systems classically consist of three major components: a wavefront sensor, a wavefront corrector, and a control system linking the prior two constituents (Fig. 1). The wavefront sensor measures the patient's ocular aberrations, whilst the control system interprets these to communicate the required adjustments to the wavefront corrector. In the closed-loop configuration conventionally used, the wavefront sensor is positioned after the wavefront corrector to provide feedback regarding residual aberrations until the wavefront matrix is minimised. This is ideally the diffraction limit of the patient's eye, however this is not always possible [28].

\section{Wavefront sensor}

The Shack-Hartmann Wavefront Sensor (SHWS) is the most commonly used wavefront measurement technique in ophthalmology. It consists of an array of micro-lenslets located in front of an area detector [29]. In the SHWS, the aberrated light leaving the eye illuminates micro-lenslets to produce an arrangement of spots on the detector. Since each

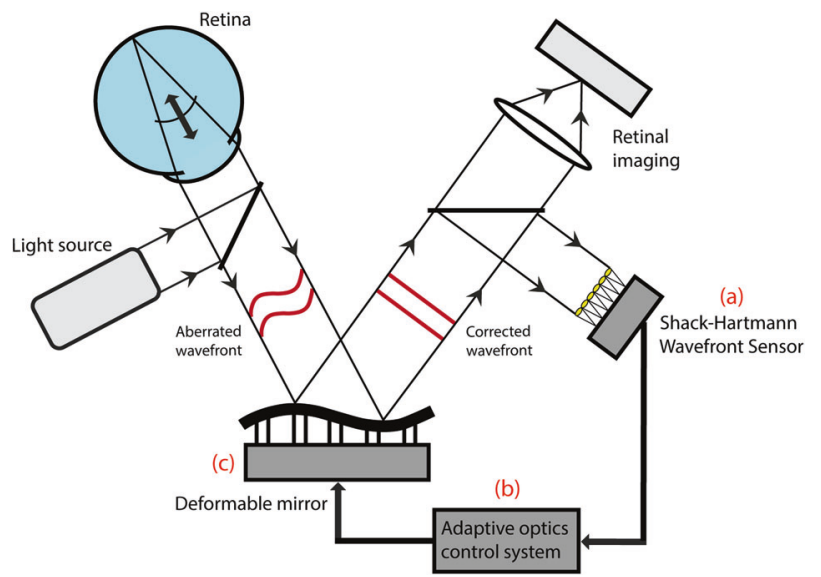

Fig. 1 Schematic diagram of an adaptive optics-assisted retinal imaging system. An AO system measures the aberrated wavefront using a wavefront sensor (a), and compensates for this using a wavefront corrector (c). These usually take the form of a Shack-Hartmann Wavefront Sensor (SHWS) and deformable mirror, respectively. These two components are connected by a central control system (b). The resulting AO-corrected retinal image is recorded using a highresolution camera

micro-lenslet corresponds to a location at the pupil, the SHWS assesses how much each detected spot position deviates from its intended position. The calculated deviation is used to make inferences about the wavefront slope and amplitude at each location and is compiled across the pupil, thus determining the type and magnitude of optical aberration across the wavefront.

\section{Wavefront corrector}

Numerous techniques are available to correct the wavefront and are generally divided into two categories: pistonsegmented devices and continuous surface mirrors. The most commonly used wavefront corrector, the deformable mirror, is comprised of a reflective faceplate deflected by a series of actuators, which can be either segmented or continuous. As the segmented deformable mirror leads to more diffraction-induced spurious effects, continuous deformable mirrors are the mainstay of use in AO retinal imaging. Over the last decade, a dual deformable mirror configuration, known as a 'woofer-tweeter system', has come into use in which the differing specifications of each mirror confers correction of a wider range of aberrations [30-33]. The woofer-tweeter arrangement involves both deformable mirrors conjugated to the plane of the pupil. In contrast, multiple groups have applied a dual-conjugate configuration in which one deformable mirror conjugates to the pupil whilst the other deformable mirror conjugates to a plane in front of the retina $[34,35]$. This enables aberration correction for a greater field of view, allowing wide-field highresolution retinal imaging. 


\section{Wavefront sensor-less systems}

More recently, a wavefront sensor-less AO correction system has been implemented in ophthalmic imaging, using image quality in place of a wavefront sensor to correct for aberrations [36-38]. Whilst this offers simplification of current AO systems, the serial assessment required of parameters, such as image sharpness, denotes an increased aberration correction time. This trade-off has implications in patients with temporally fluctuating aberrations or eye movements (nystagmus). Efforts are thus being made to reduce the time required for wavefront sensor-less correction to allow its application to become more widespread. This reduction is being spurred by the continual increase of computing power (CPU cores) and newer array-based computing possibilities (GPU) [39].

\section{Retinal imaging modalities using adaptive optics}

\section{Adaptive optics flood illumination ophthalmoscopy}

The first published AO retinal images were produced at the University of Rochester in 1997, where this technique was incorporated in FIO [1]. Its original applications were to understand cone density and arrangement underlying psychophysical responses. It was several years before AO use in retinal imaging progressed from understanding normal vision, to investigating retinal pathology [40]. Further complicating the uptake of AO-based imaging in ophthalmic practice was the reliance on custom-built systems, oversized for the clinical setting. However, the first compact AO retinal imaging system became commercially available in 2011 in the form of the rtx1 (Imagine Eyes, France), providing a $4 \times 4^{\circ}(\sim 1.3 \times \sim 1.3 \mathrm{~mm})$ retinal view [41].

The advantages of AO-FIO include its incorporation of a spinning diffuser to eliminate speckle from its light source. Conversely, it is limited by a poor axial resolution $(\sim 300$ $\mu \mathrm{m})$, which reduces cone photoreceptor contrast and decreases repeatability of longitudinal cone density measurements $[42,43]$. The efficiency of AO-FIO was previously restricted by its long imaging time per frame due to light source and detector technologies. However, the advent of the superluminescent diode (SLD) as a light source, paired with a high-speed charge-coupled device, has enabled faster frame rates [16]. This has conferred AO-FIO with the capacity to record real-time retinal videos, particularly in the context of retinal perfusion [44]. In one of the earliest studies of its use in IRDs, Choi et al. [45] employed AO-FIO to directly correlate the extent of cone abnormalities with functional loss of vision in patients with retinal dystrophy.
Adaptive optics scanning laser ophthalmoscopy

The next AO ophthalmic imaging breakthrough arrived in the form of the AOSLO in 2002 [18], which improved upon the AO-FIO's image contrast and added the ability to optically section. In AOSLO, a single-point light beam is raster scanned across the retina, with scattered light from each point recorded by a light-sensitive detector to construct an image. This system allows the incorporation of multiple detection modes, including confocal, offset pinhole and non-confocal methods. In confocal imaging, a pinhole is positioned in front of the detector, which allows the rejection of light scattered from areas other than those within the retinal focal plane. As a result, the image at the point of focus is of significantly greater contrast and allows a system to be designed that enables retinal sectioning. Confocal AOSLO is particularly useful in permitting the imaging of rod photoreceptors $[10,46,47]$ and elements of the optic nerve, including the nerve fibre layer [48] and lamina cribrosa [49].

Over the last 5 years, the advantages of non-confocal AOSLO have also emerged. In contrast to confocal AOSLO, this involves collecting scattered light surrounding the point of focus instead of the confocal signal itself. The resultant annular signal enables effective visualisation of the RPE without the need for autofluorescence, known as 'darkfield imaging' [15]. Alternatively, this signal can be divided in two to reveal inner segments of photoreceptors not seen on confocal AOSLO, termed 'split-detection imaging' (Fig. 2) [50]. This confers advantages in IRDs in which photoreceptor outer segment (OS) composition and alignment are affected, such as achromatopsia [51], choroideremia [52], Stargardt disease [53], and Leber congenital amaurosis [54]. There is, therefore, strong rationale for the complementary use of both confocal and non-confocal AOSLO in the assessment of retinal structure, especially in IRDs (Fig. 3) [23, 55-57]. Disadvantages of AOSLO include its propensity for image distortion, as well as the inefficiency of its serial image creation [58].

\section{Adaptive optics optical coherence tomography}

The latest advent in retinal imaging has been the incorporation of AO in OCT. Now in widespread clinical use, the introduction of OCT in 1991 made possible a crosssectional view of the retina previously only seen ex vivo as a histological section [59]. Although native OCT provides a subcellular axial optical resolution, its axial and transverse resolution is still limited by optical aberrations, thus making its partnership with AO ideal. AO-OCT has facilitated three-dimensional visualisation of single photoreceptors [60], retinal nerve fibre bundles [61], the lamina cribrosa [62], and retinal vasculature [63]. An exciting recent 

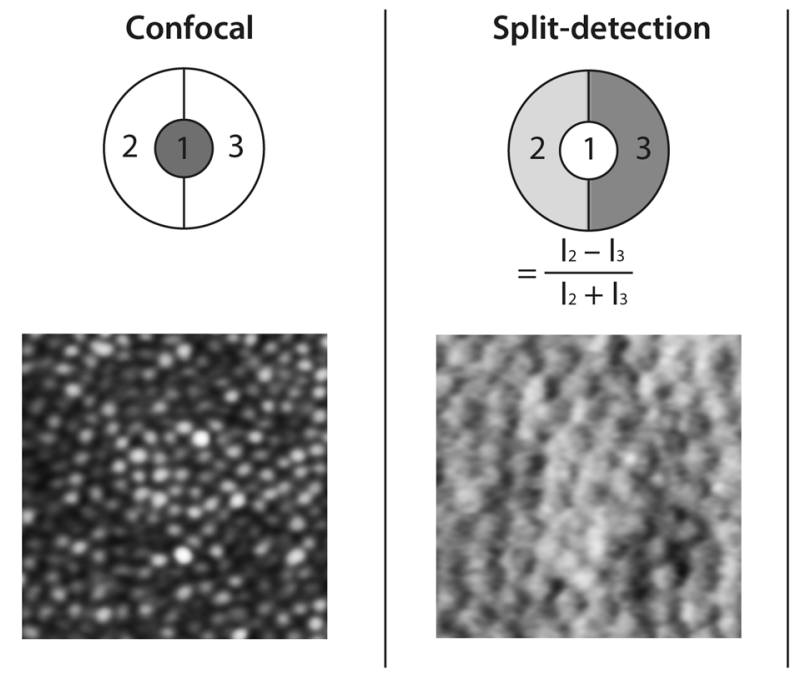

Dark-field

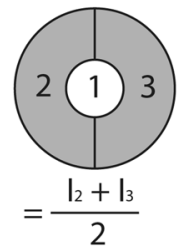

Fig. 2 Comparison of detection modes using adaptive optics scanning laser ophthalmoscopy (AOSLO) in healthy retina. Detector views of the annular reflective mirror (top) represent the relative contributions of scattered/non-scattered light in producing each AOSLO modality image (bottom). Confocal imaging utilises light within the retinal focal plane, whereas non-confocal (split-detection and dark-field) images are

produced from scattered light. Individual photoreceptor cells can be identified on both confocal and split-detection imaging. Dark-field imaging reveals the underlying retinal pigment epithelium (RPE) as a hexagonal mosaic. The AOSLO images shown are from different retinal locations in the same healthy eye

development is the simultaneous use of AOSLO and AOOCT, which offers the ultrahigh axial resolution of the latter whilst utilising eye tracking advantages of the former to reduce the effect of saccade $[13,64]$.

\section{The effect of optical resolution and image sampling on cell visibility}

One challenge in understanding the AO imaging literature has been discrepancies in interpretations of the same disease, due to differences in capabilities between the various AO-enabled platforms and devices [56, 57, 65-68]. These variations may be initially interpreted as inherent differences in resolution across AO imaging modalities. However, this is more often due to a difference in image sampling, rather than optical resolution. For instance, foveal cones and near-fovea rods $(<2$ $\mathrm{mm}$ from centre) are roughly $2 \mu \mathrm{m}$ in diameter [69], which is near the theoretical optical resolution for a nominal eye $[70,71]$. Rod photoreceptors change in size modestly, reaching roughly $2-4 \mu \mathrm{m}$ in the peripheral retina $(>8 \mathrm{~mm}$ from centre). In comparison, cone photoreceptors markedly increase in diameter from their $2 \mu \mathrm{m}$ foveal size, to $>10 \mu \mathrm{m}$ by $3 \mathrm{~mm}$ from the centre of fixation $[69,72]$. The differences in photoreceptor diameter have contributed towards their variable visibility across modalities. Rod photoreceptors were first observed in IRD patients using FIO technology [73] in 2006, and seen using the same technology in normal subjects in early 2011 [74], before first being published using AOSLO [10] later that year. Subsequently, rods have also been visualised using AO-OCT methods [13, 60]. Many of the early FIO systems had a sampling resolution between $1-2 \mu \mathrm{m}$

per pixel, including commercially available systems [11]. Alternatively, custom built AOSLO systems have been designed with sub-micron sampling resolutions [71, 75] which, due to Nyquist limits and contrast enhancements from confocal imaging [76], are better positioned to take advantage of and achieve the theoretical limits of resolution. Therefore, the common differences observed between modalities to date has been due to differences in image sampling. The interaction between sampling, optical resolution and device design has been reviewed elsewhere [70, 71].

\section{Applications of adaptive optics in inherited retinal diseases}

The application of AO in IRDs has progressed from exploring disease genotype-phenotype correlations [77-79], to longitudinal assessment of disease progression using cellular metrics as potential trial endpoints $[2-4,80]$. To enable the latter, AO-aided imaging has demonstrated the ability to image the same retinal area with microscopic precision longitudinally [81, 82]. Several aspects of retinal microstructure, such as photoreceptor density and morphology, have consequently emerged as significant to the disease process and assisted in characterisation of each condition. These have been proposed as metrics for evaluating therapeutic potential and efficacy in patients $[83,84]$, and are therefore of great clinical relevance.

To understand the differences between normal and abnormal cell densities, an understanding of normal 


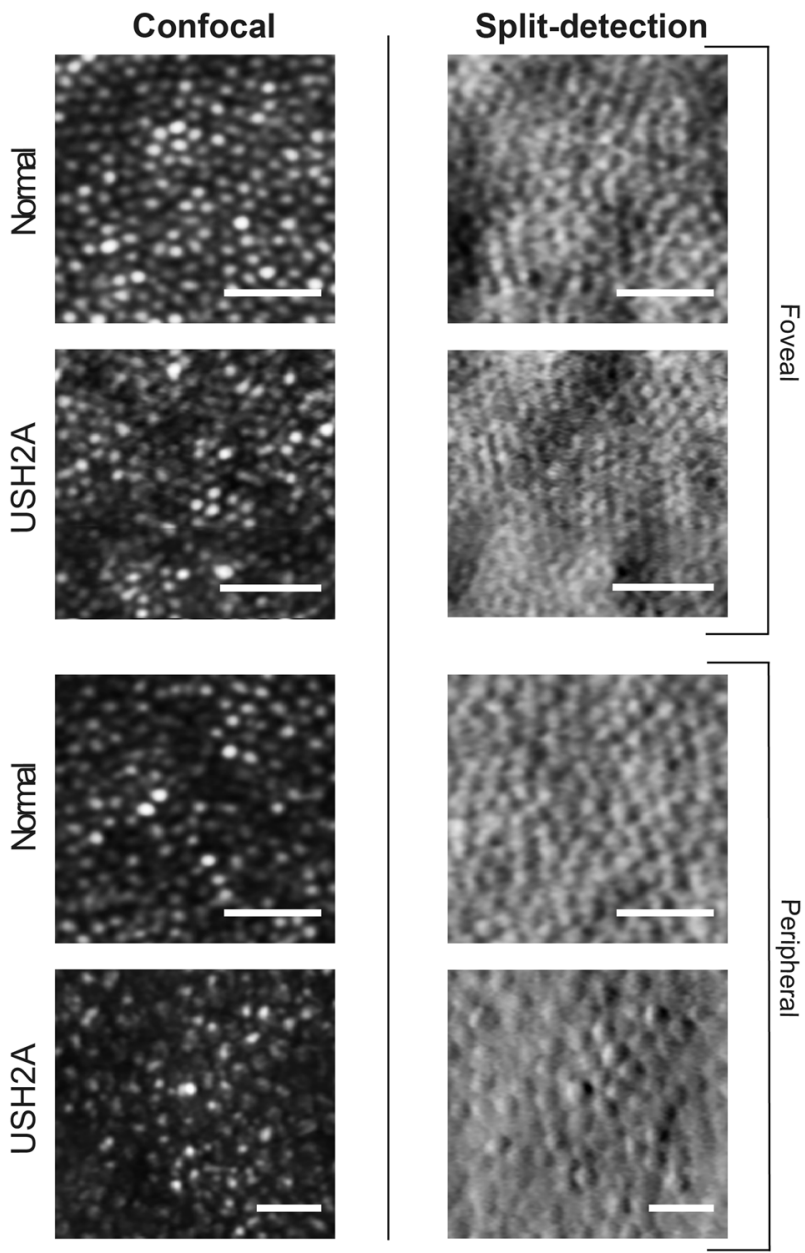

Fig. 3 Comparison of confocal and non-confocal (split-detection) AOSLO in a healthy control and an USH2A-associated type II Usher syndrome patient. AOSLO imaging of a 35 -year-old male healthy control shows a regular and densely packed photoreceptor mosaic at the fovea (top left), with larger and less dense photoreceptors in the periphery. Although these photoreceptors demonstrate varying degrees of reflectance, there are no prominent dark regions. In contrast, imaging of a 43-year-old female with $U S H 2 A$-associated retinitis pigmentosa reveals a disrupted foveal mosaic with non-waveguiding areas, which increases in severity peripherally. Split-detection imaging (bottom right) of non-waveguiding areas in the peripheral confocal mosaic (bottom left) shows remnant cone inner segments in this patient. Scale bar $=10 \mu \mathrm{m}$

variability must be assessed. Most optical imaging literature still refer back to the seminal histological work by Curcio et al. [69], to assess the density and organisation of the rod and cone photoreceptors. Several groups have since looked at larger cohorts of healthy retina using AO-aided imaging, and have now developed extensive normal subject photoreceptor density data [10, 82, 85-87]. It is largely agreed that the very centre of the fovea is rod-free, expanding out to a region of $250-500 \mu \mathrm{m}$ in diameter $[69,88]$. Cone photoreceptor density drops precipitously from $\sim 300,000$ to 100,000 photoreceptors per $\mathrm{mm}^{2}$ as you move from the centre to the edge of this region $(\sim 50 \%$ less $)$
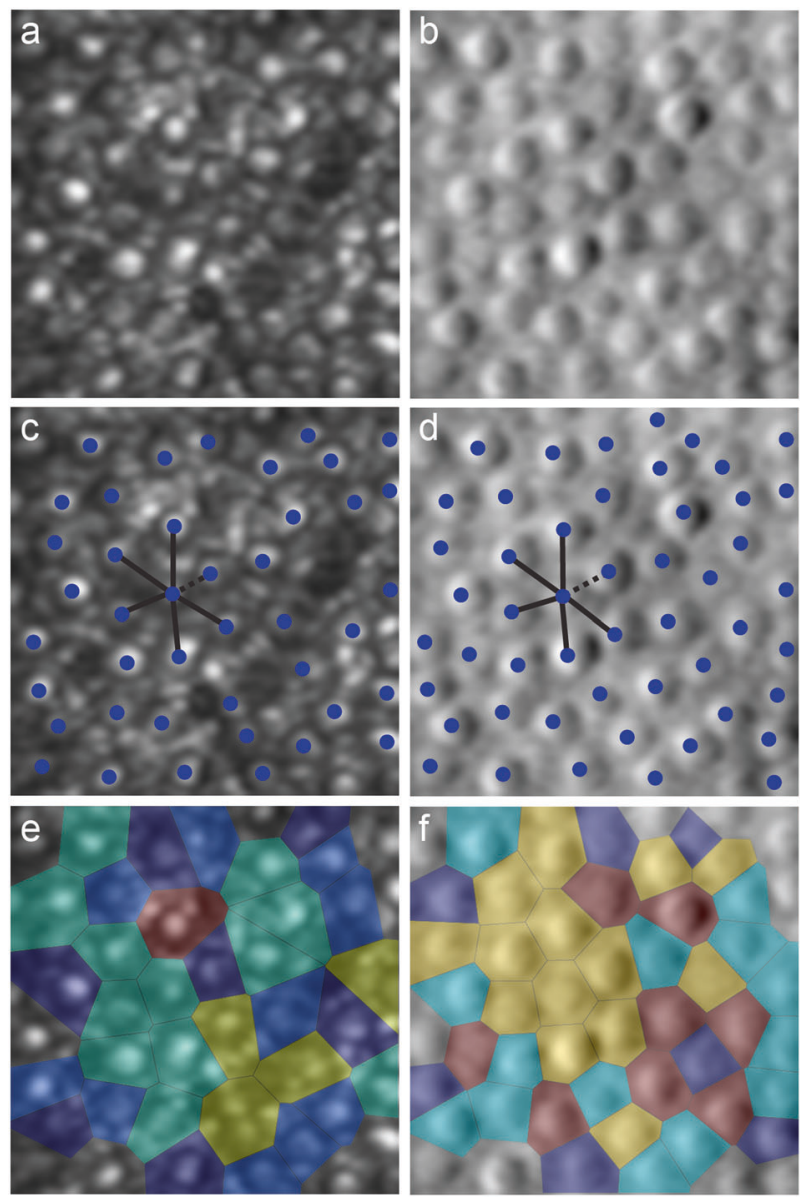

Fig. 4 Application of photoreceptor mosaic-based metrics. Shown here are simultaneously acquired confocal (a) and split-detection (b) AOSLO images. Photoreceptors can be directly identified using automated or manual methods (blue spots) in the confocal (c) and split-detection (d) image. The modalities provide different rates of identifiable cones. Once cone centres are identified, the nearest neighbour distance (dashed line) or mean inter-cone distance (average of all lines) can be measured. Additional metrics include Voronoi diagrams of the foveal cone photoreceptors $(\mathbf{e}, \mathbf{f})$, the colouration of which is used to illustrate the number of neighbours each cell has surrounding it

$[69,72,82,88]$. The photoreceptor density continues to drop to nominally $5000 \mathrm{~mm}^{2}$ by $3 \mathrm{~mm}$ from the centre, but this is affected by several factors such as axial length [69, 82, 85]. Over the same area, rod photoreceptors transition from absence at the centre to a peak of 125,000 rods per $\mathrm{mm}^{2}$ at about $4 \mathrm{~mm}$ radius, before slowly decreasing in density as you move to the far periphery.

\section{Photoreceptor-based metrics}

The ideal photoreceptor mosaic is organised in a regular triangular lattice with hexagonal packing [89]. Several metrics aim to detect and quantify photoreceptor loss in this arrangement, and can be broadly categorised into measures of density, spacing and regularity (Fig. 4) [90]. Cone 
Fig. 5 Multimodal imaging of USH2A-associated type II Usher syndrome. (a) Infrared reflectance (IR) fundus photograph, with the central red arrow representing the optical coherence tomography (OCT) section shown in (b). (c) Fundus auto-fluorescence (FAF) photograph with confocal adaptive optics scanning laser ophthalmoscopy (AOSLO) imaging of the fovea and its surrounding region superimposed and magnified in (d). Further magnification of a peripheral area (dashed rectangle) in the confocal image (e), and its corresponding AOSLO split-detection image (f), shows intact photoreceptor inner segments in nonwaveguiding areas of the confocal mosaic (yellow arrows)
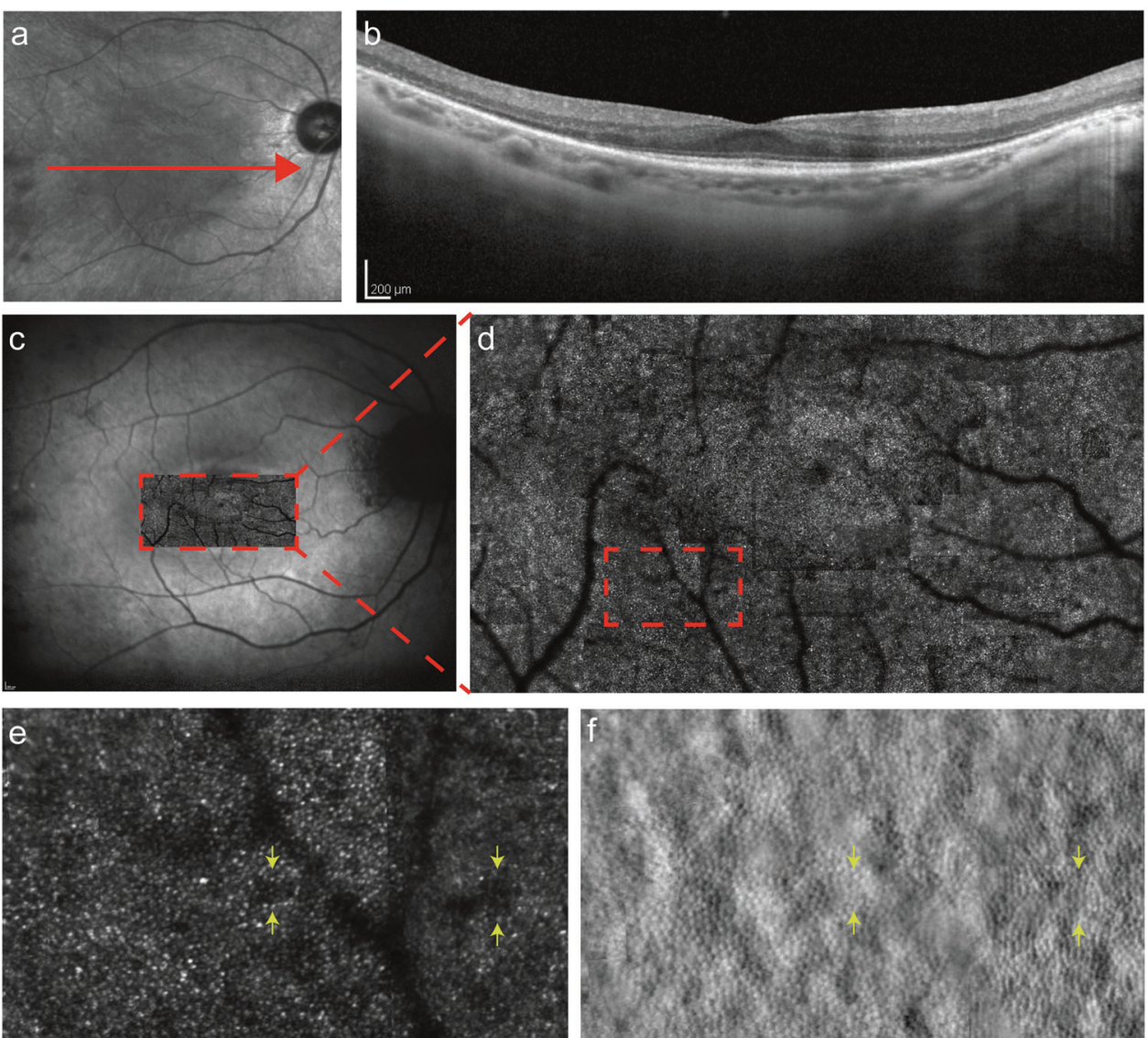

density is the most commonly used mosaic metric, with good reliability and repeatability established in healthy controls [91-93]. However, the comparative difficulty of cone identification in retinal degenerations has rendered this metric variable when applied to patients with Stargardt disease [94], RPGR-associated retinopathy [94], and achromatopsia [79]. In addition to inter-disease variances, several studies demonstrate inter-imaging modality differences in cone density reliability, with split-detector AOSLO conferring the best results $[94,95]$. Limitations in reliability and repeatability are similarly reported for cone spacing metrics in IRDs [96], largely due to differences in mosaic sampling window size and areas with increased cone reflectivity loss. Nevertheless, both cone density and spacing were successfully used by Talcott et al. [97] as measures of treatment efficacy in patients with retinitis pigmentosa (RP) and Usher syndrome, in which ciliary neurotrophic factor administration led to a reduced rate of cone loss.

Photoreceptor reflectance properties have also been explored for their utility as cellular metrics. On viewing the in vivo retina using confocal AOSLO, bright Gaussian profiles representing individual waveguiding photoreceptors are visible, with their intensity exhibiting temporospatial variation $[46,98]$. The degree of cone illumination is proposed to reflect OS function [99], and is supported by functional imaging studies demonstrating stimulus-evoked increases in cone brightness [100-102]. In the context of IRDs, Dubis et al. [83] validated cone reflectance as a functional metric in achromatopsia by correlating greater mean cone reflectivity with better residual cone function. In corroboration with this, a hyporeflective annulus surrounding a central region of atrophy was noted in Stargardt disease, which correlated with areas of cone loss [103]. However, occurrence of rod hyperreflectivity in Oguchi disease [104] supports an alternative hypothesis linking photoreceptor intensity to their OS length [105], which are reported as shortened in this condition [106]. Raising further questions regarding the validity of this metric, Bruce et al. [107] reported weakly waveguiding cones in healthy retina which performed normally on functional testing with cone-based microperimetry.

Finally, AO imaging may be used to quantify morphological changes in individual photoreceptors during the degeneration process [108], namely in OS length and inner segment (IS) diameter. Jonnal et al. [109] recently devised a method using phase-sensitive AO-OCT to detect changes in OS length down to $45 \mathrm{~nm}$, whilst Liu et al. [55] have utilised split-detection AOSLO to measure remnant cone IS. Despite its use as a marker by Sun et al. in RP [23] and choroideremia [57], the utility of IS diameter is confounded by enlargement of some cones secondary to neighbouring 
Fig. 6 Multimodal imaging of CHM-associated choroideremia. (a) IR fundus photograph, with the central red arrow representing the OCT section shown in (b). (c) FAF photograph with confocal AOSLO imaging of the fovea and its surrounding region superimposed and magnified in (d). Further magnification of a perifoveal area (dashed rectangle) in the confocal image (e), and its corresponding AOSLO splitdetection image (f), shows a wellcircumscribed island of intact photoreceptors surrounded by non-waveguiding cones (red arrows). Intact photoreceptor inner segments are seen in nonwaveguiding areas of the confocal mosaic (yellow arrows)
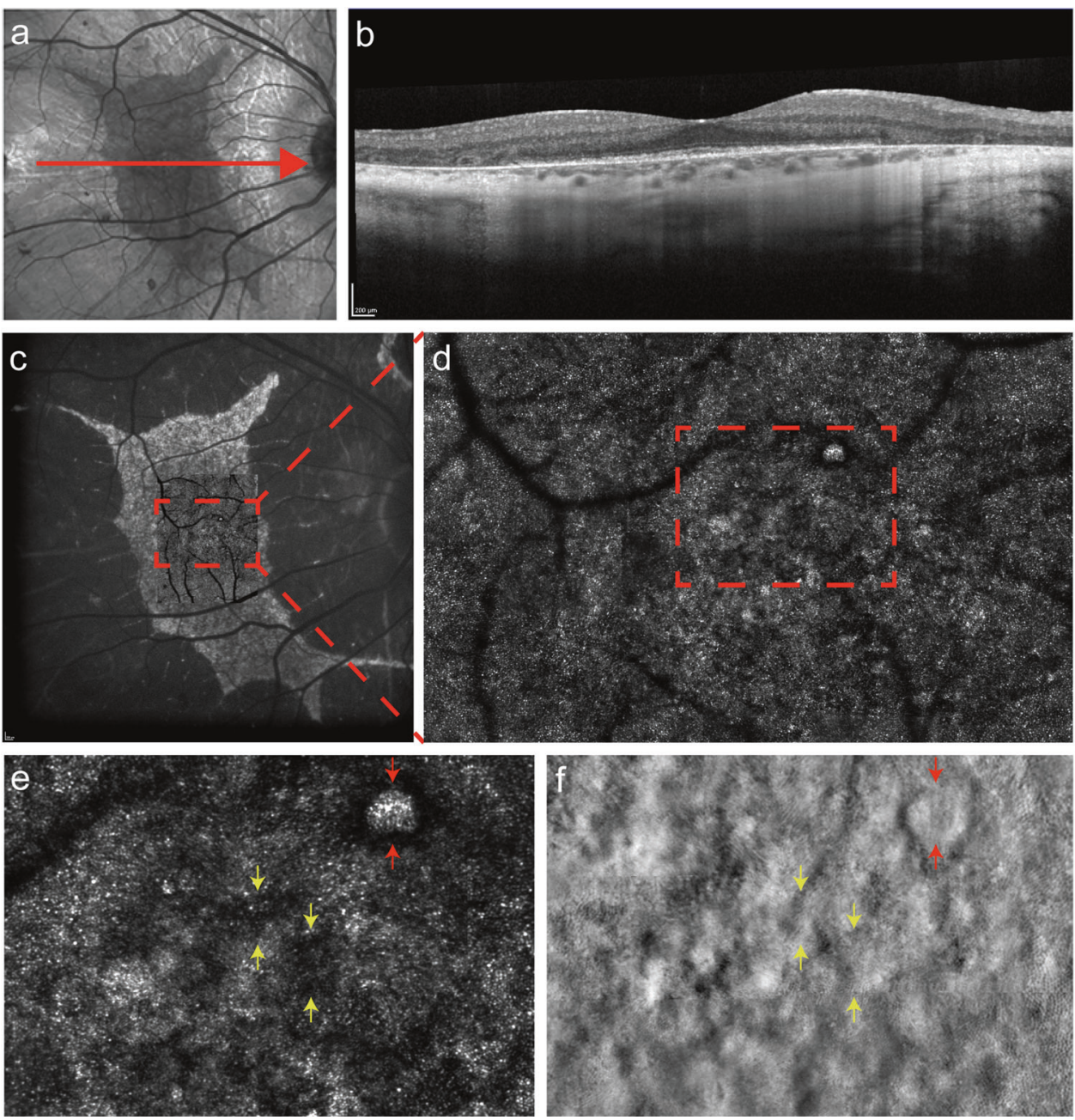

cone loss rather than their own degeneration [110]. Further studies using morphology-based metrics are required to better elucidate their utility.

\section{RPE-based metrics}

The use of RPE-based metrics for retinal diseases is one of the most recent and exciting research avenues in AO-based imaging. The RPE maintains a close structural and functional relationship with its adjacent photoreceptors, holding essential roles in OS phagocytosis, the visual cycle, light absorption and transepithelial transport [111, 112]. In spite of its dysfunction and/or atrophy underlying multiple IRDs, including RP [113], biomarkers signifying its change have been limited. This is mainly attributable to difficulty in its direct visualisation, first being imaged after the degeneration of its overlying photoreceptors [114]. However, Liu et al. [14] recently applied AO-OCT to provide threedimensional characterisation of RPE cells, proposing quantification of their organelle motility as a functional metric [115]. Potential for RPE density as a biomarker has also emerged by implementation of $\mathrm{AO}$ in infrared autofluorescence imaging (AO-IRAF) [116]. Application of AO-IRAF in an RP patient delivered a resolution that enabled precise calculation of RPE density and RPE-tophotoreceptor ratio.

\section{Comparison of metrics}

Selection of the 'best' metric in a patient or clinical study is based on two factors: its functional relevance, and its sensitivity in detecting change. At present, both are only wellcharacterised in photoreceptor mosaic-based metrics [90]. Morphology- and RPE-based metrics are relatively well understood regarding their structure-function relationships, but warrant further exploration to assess their sensitivity and robustness. Photoreceptor reflectance, on the other hand, remains ambiguous in both its origin and utility. Although based on data from healthy controls, Cooper et al. [90] showed significantly greater sensitivity of mosaic regularity metrics in identifying cone loss than of spacing metrics, suggesting 
Fig. 7 Multimodal imaging of MYO7A-associated type I Usher syndrome. (a) IR fundus photograph, with the central red arrow representing the OCT section shown in (b). (c) FAF photograph with confocal AOSLO imaging of the fovea and its surrounding region superimposed and magnified in (d). Further magnification of a peripheral area (dashed rectangle) in the confocal image (e), and its corresponding AOSLO split-detection image (f), shows the demarcation line between a contiguous mosaic of intact photoreceptors and their degenerating neighbours (dashed arc). It is important to note the stark contrast above and below this arc on the splitdetection image (f), compared to the lack of difference in the confocal image (e)
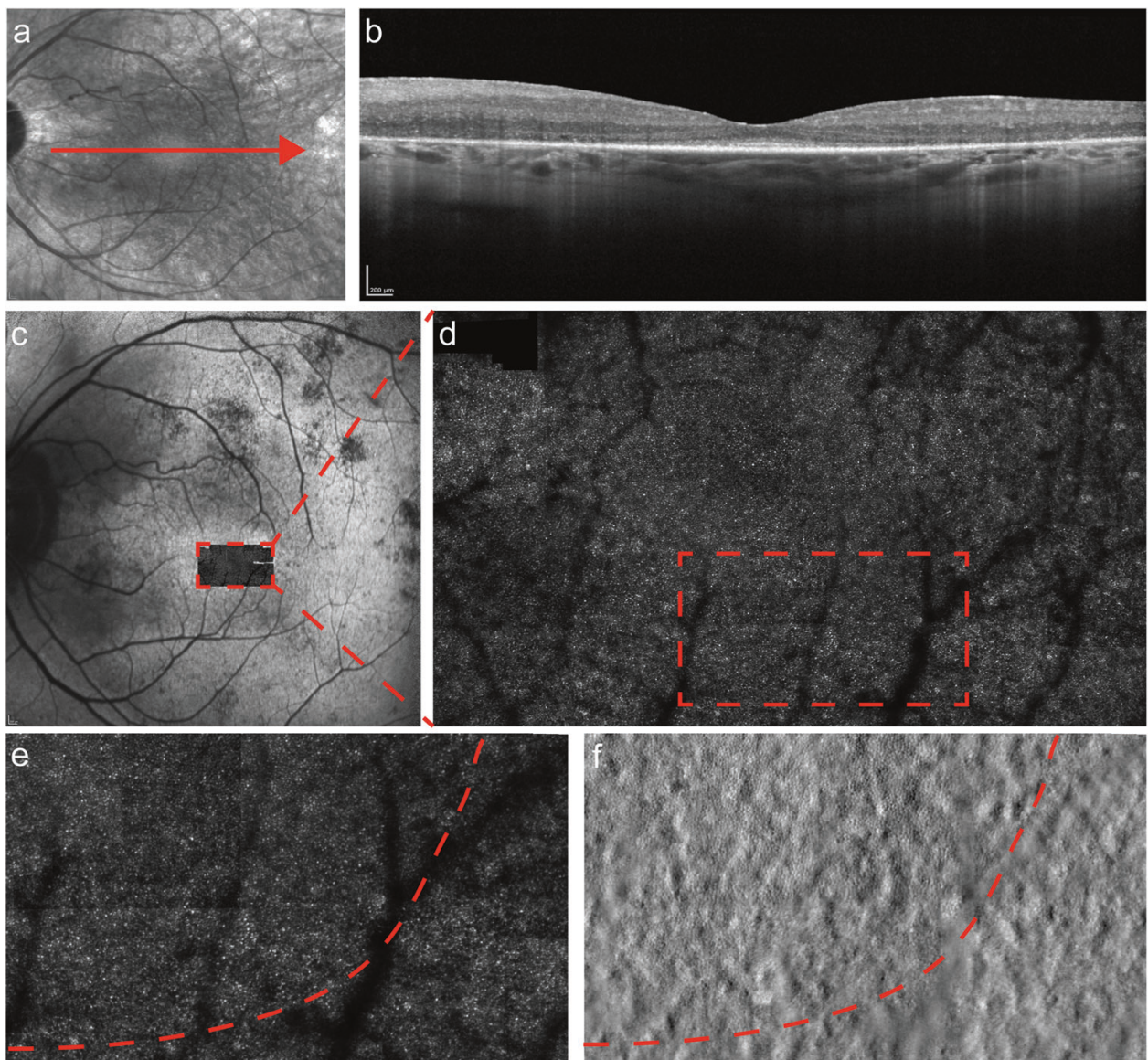

their utility in longitudinal disease monitoring. However, combining multiple metrics, as opposed to using a single measure, may confer the greatest accuracy in monitoring retinal disease [87, 117].

A major issue in the comparison of metrics, and in their robust application, is the lack of multicentre standardisation. This includes the absence of a central normative dataset to assess findings against, as well as variation in the size of retinal sampling windows used. These differences can cause discrepancies in results, and thus prevent us from assimilating data from different research groups when evaluating metric utility.

\section{Findings using adaptive optics in inherited retinal diseases}

AO-based imaging allows clinical diagnosis from early pathological changes and disease monitoring using the aforementioned metrics, thus conferring advantages that imaging systems prior to it had been unable to offer. The use of AO to study abnormalities in IRDs in conjunction with established imaging methods has enabled the cellular characterisation of these conditions (Figs. 5-7). We have collated the phenotypic findings for each IRD investigated thus far and categorised them based on their monogenetic disease-causing gene (Table 1). This provides a comprehensive and up-to-date summary of AO imaging findings in the IRDs.

\section{Limitations and future prospects}

The heterogeneity and rare prevalence of IRDs necessitates larger cohort sizes in AO-based clinical studies, for which multicentre collaborations are required [118]. However, inter-centre discrepancies, in the form of differing AO-aided imaging modalities and image acquisition methods, complicate collaborative efforts. Aside from difficulties in accurate cone identification, the impracticality of manual image grading by observers and its poor repeatability can also render metric applications as unreliable [95]. Recent efforts to produce automated analytic tools for AO images have shown promise in both confocal and non-confocal settings $[119,120]$, with the latter being used in achromatopsia and Stargardt disease [121, 122]. Although further work is needed to characterise the performance of these algorithms in relation to different metrics [123], this 


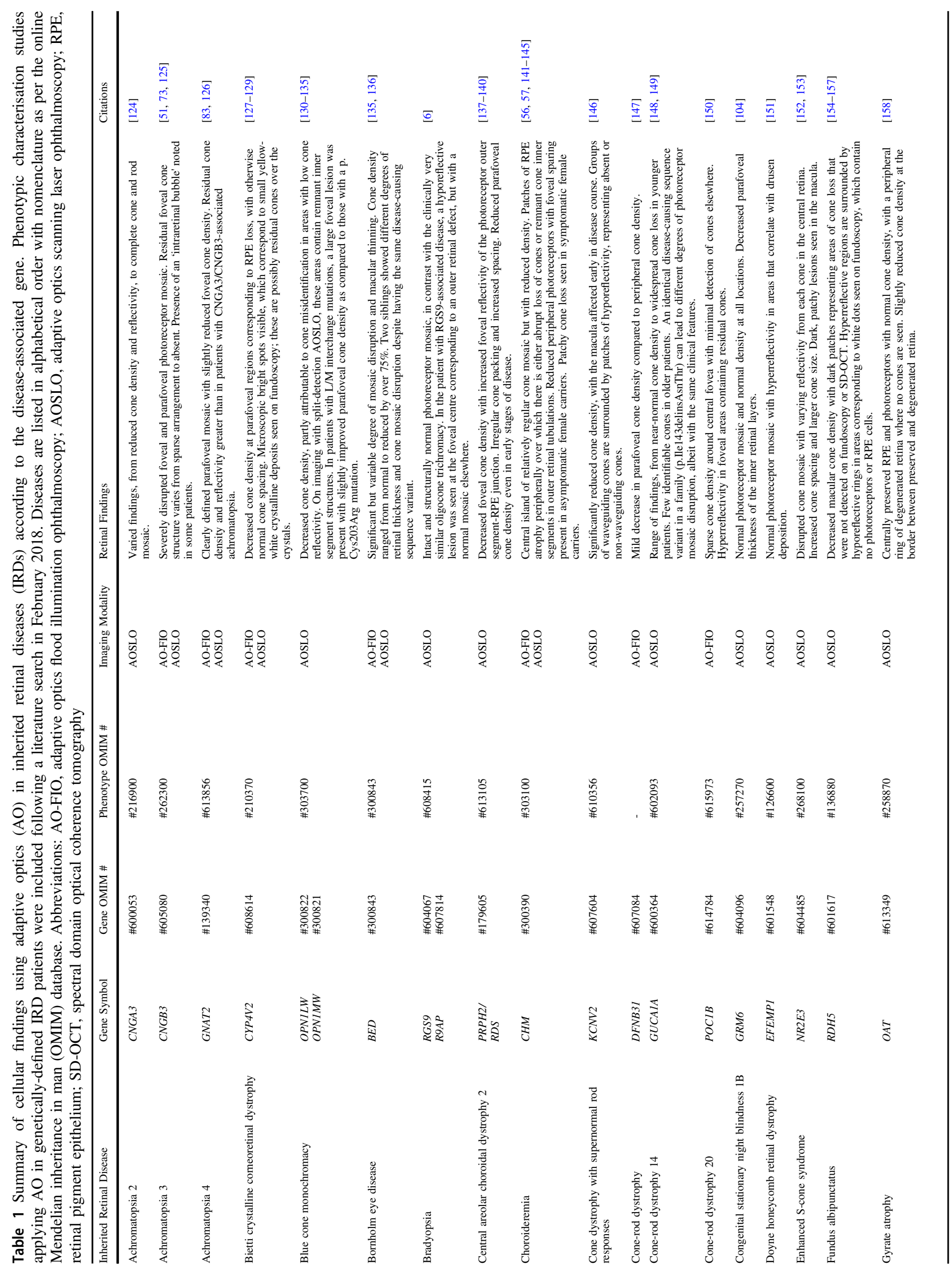




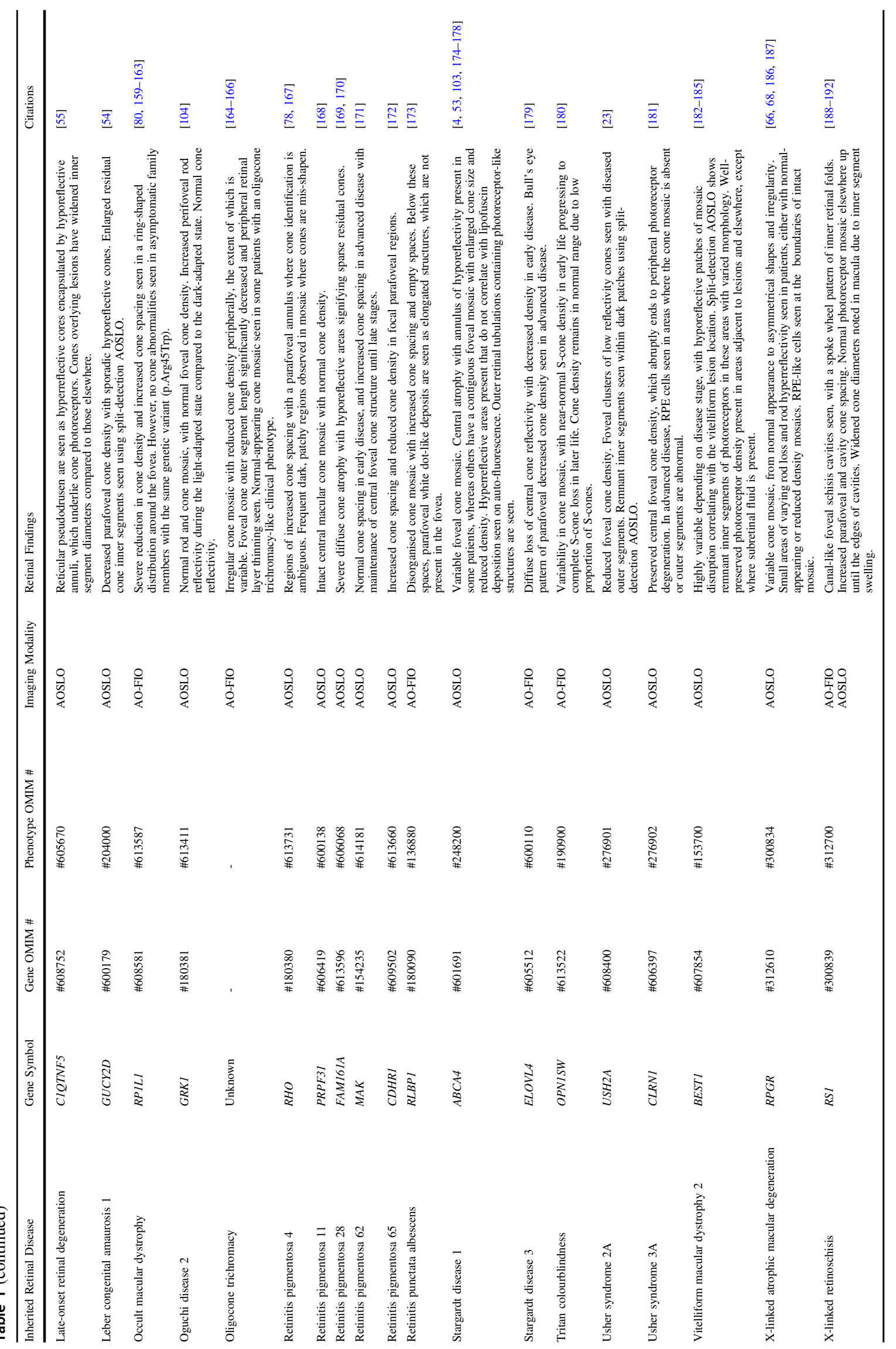


provides AO retinal imaging with good prospects in fulfilling their clinical potential.

In summary, the correction of optical aberrations using adaptive optics has enabled high-resolution microscopic visualisation of the living retina, thereby furthering our understanding of IRD pathogenesis. Despite drawbacks in cost and technical complexity, the benefits of applying AO in this context are vast, including early diagnosis, detection of subclinical disease changes, patient stratification for treatment and assessment of treatment efficacy. The challenge for the coming years is in transferring this tool from the research laboratory to the clinical setting, where it could transform patient outcomes in both the IRDs and other retinal diseases.

\section{Method of literature search}

A literature search was conducted in February 2018 using the term 'adaptive optics' on Pubmed in combination with each of the following key terms: 'retinal imaging', 'retina', 'cones' and 'photoreceptors'. This generated 687 publication results, of which 79 were directly related to IRDs. For each IRD, the condition name (e.g. Stargardt disease) was additionally searched in conjunction with 'adaptive optics' on Pubmed. Finally, abstracts presented at previous Association for Research in Vision and Ophthalmology (ARVO) annual meetings were reviewed using the search term 'adaptive optics'. This yielded 1,602 results, of which 81 were directly related to IRDs.

Acknowledgements This work was supported by the National Institute for Health Research Biomedical Research Centre at Moorfields Eye Hospital National Health Service Foundation Trust and UCL Institute of Ophthalmology (UK), and the Wellcome Trust (UK).

\section{Compliance with ethical standards}

Conflict of interest The authors declare that they have no conflict of interest.

Publisher's note: Springer Nature remains neutral with regard to jurisdictional claims in published maps and institutional affiliations.

Open Access This article is licensed under a Creative Commons Attribution 4.0 International License, which permits use, sharing, adaptation, distribution and reproduction in any medium or format, as long as you give appropriate credit to the original author(s) and the source, provide a link to the Creative Commons license, and indicate if changes were made. The images or other third party material in this article are included in the article's Creative Commons license, unless indicated otherwise in a credit line to the material. If material is not included in the article's Creative Commons license and your intended use is not permitted by statutory regulation or exceeds the permitted use, you will need to obtain permission directly from the copyright holder. To view a copy of this license, visit http://creativecommons. org/licenses/by/4.0/.

\section{References}

1. Liang J, Williams DR, Miller DT. Supernormal vision and highresolution retinal imaging through adaptive optics. J Opt Soc Am A Opt Image Sci Vis. 1997;14:2884-92.

2. Langlo CS, Collison FT, Summerfelt P, et al. Longitudinal imaging of foveal cone structure in congenital achromatopsia. Invest Ophthalmol Vis Sci. 2015;56:4017-4017.

3. Langlo CS, Erker LR, Parker M, et al. Repeatability and longitudinal assessment of foveal cone structure in Cngb3-associated achromatopsia. Retina. 2017;37:1956-66.

4. Reback MA, Song H, Latchney LR, Chung MM. Longitudinal adaptive optics imaging reveals regional variation in cone and rod loss in Stargardt disease. Invest Ophthalmol Vis Sci. 2015;56:4929-4929.

5. Makiyama Y, Ooto S, Hangai M, et al. Macular cone abnormalities in retinitis pigmentosa with preserved central vision using adaptive optics scanning laser ophthalmoscopy. PLoS One. 2013;8:e79447.

6. Strauss RW, Dubis AM, Cooper RF, et al. Retinal architecture in RGS9 and R9AP-associated retinal dysfunction (Bradyopsia). Am J Ophthalmol. 2015;160:1269-75 e1261.

7. Babcock HW. Adaptive optics revisited. Science. 1990;249: 253-7.

8. Liu Z, Kurokawa K, Zhang F, Lee JJ, Miller DT. Imaging and quantifying ganglion cells and other transparent neurons in the living human retina. Proc Natl Acad Sci USA. 2017;114:12803-8.

9. Prasse M, Rauscher FG, Wiedemann P, Reichenbach A, Francke M. Optical properties of retinal tissue and the potential of adaptive optics to visualize retinal ganglion cells in vivo. Cell Tissue Res. 2013;353:269-78.

10. Dubra A, Sulai Y, Norris JL, et al. Noninvasive imaging of the human rod photoreceptor mosaic using a confocal adaptive optics scanning ophthalmoscope. Biomed Opt Express. 2011;2:1864-76.

11. Lombardo M, Lombardo G, Ducoli P, Serrao S. Adaptive optics photoreceptor imaging. Ophthalmology. 2012;119:1498-1498 e1492.

12. Muthiah MN, Gias C, Chen FK, et al. Cone photoreceptor definition on adaptive optics retinal imaging. Br J Ophthalmol. 2014;98:1073-9.

13. Felberer F, Kroisamer JS, Baumann B, et al. Adaptive optics SLO/OCT for 3D imaging of human photoreceptors in vivo. Biomed Opt Express. 2014;5:439-56.

14. Liu Z, Kocaoglu OP, Miller DT. 3D imaging of retinal pigment epithelial cells in the living human retina. Invest Ophthalmol Vis Sci. 2016;57:OCT533-543.

15. Scoles D, Sulai YN, Dubra A. In vivo dark-field imaging of the retinal pigment epithelium cell mosaic. Biomed Opt Express. 2013;4:1710-23.

16. Rha J, Jonnal RS, Thorn KE, Qu J, Zhang Y, Miller DT. Adaptive optics flood-illumination camera for high speed retinal imaging. Opt Express. 2006;14:4552-69.

17. Burns SA, Tumbar R, Elsner AE, Ferguson D, Hammer DX. Large-field-of-view, modular, stabilized, adaptive-optics-based scanning laser ophthalmoscope. J Opt Soc Am A Opt Image Sci Vis. 2007;24:1313-26.

18. Roorda A, Romero-Borja F, Donnelly Iii W, Queener H, Hebert T, Campbell M. Adaptive optics scanning laser ophthalmoscopy. Opt Express. 2002;10:405-12.

19. Hermann B, Fernandez EJ, Unterhuber A, et al. Adaptive-optics ultrahigh-resolution optical coherence tomography. Opt Lett. 2004;29:2142-4.

20. Zhang Y, Rha J, Jonnal R, Miller D. Adaptive optics parallel spectral domain optical coherence tomography for imaging the living retina. Opt Express. 2005;13:4792-811. 
21. Berger W, Kloeckener-Gruissem B, Neidhardt J. The molecular basis of human retinal and vitreoretinal diseases. Prog Retin Eye Res. 2010;29:335-75.

22. Ratnam K, Carroll J, Porco TC, Duncan JL, Roorda A. Relationship between foveal cone structure and clinical measures of visual function in patients with inherited retinal degenerations. Invest Ophthalmol Vis Sci. 2013;54:5836-47.

23. Sun LW, Johnson RD, Langlo CS, et al. Assessing photoreceptor structure in retinitis pigmentosa and usher syndrome. Invest Ophthalmol Vis Sci. 2016;57:2428-42.

24. Bennett J. Taking Stock of Retinal Gene Therapy: Looking Back and Moving Forward. Mol Ther 2017;25:1076-1094

25. Lombardo M, Lombardo G. Wave aberration of human eyes and new descriptors of image optical quality and visual performance. J Cataract Refract Surg. 2010;36:313-31.

26. Holladay JT, Lynn MJ, Waring GO 3rd, Gemmill M, Keehn GC, Fielding B. The relationship of visual acuity, refractive error, and pupil size after radial keratotomy. Arch Ophthalmol. 1991;109: $70-6$.

27. Guirao A, Artal P. Corneal wave aberration from videokeratography: accuracy and limitations of the procedure. J Opt Soc Am A Opt Image Sci Vis. 2000;17:955-65.

28. Sabesan R, Yoon G. Visual performance after correcting higher order aberrations in keratoconic eyes. J Vis. 2009;9:1-10.

29. Liang J, Grimm B, Goelz S, Bille JF. Objective measurement of wave aberrations of the human eye with the use of a HartmannShack wave-front sensor. J Opt Soc Am A Opt Image Sci Vis. 1994;11:1949-57.

30. Chen DC, Jones SM, Silva DA, Olivier SS. High-resolution adaptive optics scanning laser ophthalmoscope with dual deformable mirrors. J Opt Soc Am A Opt Image Sci Vis. 2007; 24:1305-12.

31. Mujat M, Ferguson RD, Patel AH, Iftimia N, Lue N, Hammer DX. High resolution multimodal clinical ophthalmic imaging system. Opt Express. 2010;18:11607-21.

32. Zawadzki RJ, Jones SM, Olivier SS, et al. Adaptive-optics optical coherence tomography for high-resolution and high-speed 3D retinal in vivo imaging. Opt Express. 2005;13:8532-46.

33. Zou W, Qi X, Burns SA. Woofer-tweeter adaptive optics scanning laser ophthalmoscopic imaging based on Lagrangemultiplier damped least-squares algorithm. Biomed Opt Express. 2011;2:1986-2004.

34. Laslandes M, Salas M, Hitzenberger CK, Pircher M. Increasing the field of view of adaptive optics scanning laser ophthalmoscopy. Biomed Opt Express. 2017;8:4811-26.

35. Thaung J, Knutsson P, Popovic Z, Owner-Petersen M. Dualconjugate adaptive optics for wide-field high-resolution retinal imaging. Opt Express. 2009;17:4454-67.

36. Hofer H, Sredar N, Queener H, Li C, Porter J. Wavefront sensorless adaptive optics ophthalmoscopy in the human eye. Opt Express. 2011;19:14160-71.

37. Polans J, Keller B, Carrasco-Zevallos OM, et al. Wide-field retinal optical coherence tomography with wavefront sensorless adaptive optics for enhanced imaging of targeted regions. Biomed Opt Express. 2017;8:16-37.

38. Wong KS, Jian Y, Cua M, Bonora S, Zawadzki RJ, Sarunic MV. In vivo imaging of human photoreceptor mosaic with wavefront sensorless adaptive optics optical coherence tomography. Biomed Opt Express. 2015;6:580-90.

39. Mocci J, Quintavalla M, Trestino C, Bonora S, Muradore R. A multi-platform CPU-based architecture for cost-effective adaptive optics systems. IEEE Transact Ind Inform. 2018;14:4431-4439.

40. Roorda A, Williams DR. The arrangement of the three cone classes in the living human eye. Nature. 1999;397:520-2.

41. Viard C, Nakashima K, Lamory B, Pâques M, Levecq X, Château $\mathrm{N}$. Imaging microscopic structures in pathological retinas using a flood-illumination adaptive optics retinal camera. SPIE BiOS. 2011;7885:488-509

42. Chew AL, Sampson DM, Kashani I, Chen FK. Agreement in cone density derived from gaze-directed single images versus wide-field montage using adaptive optics flood illumination ophthalmoscopy. Transl Vis Sci Technol. 2017;6:9.

43. Feng S, Gale MJ, Fay JD, et al. Assessment of different sampling methods for measuring and representing macular cone density using flood-illuminated adaptive optics. Invest Ophthalmol Vis Sci. 2015;56:5751-63.

44. Gofas-Salas E, Grieve K, Zwillinger S, et al. Wide field $200 \mathrm{~Hz}$ videos of human retinas with PARIS's AO-FIO. J Vis. 2017;17: $42-42$.

45. Choi SS, Doble N, Hardy JL, et al. In vivo imaging of the photoreceptor mosaic in retinal dystrophies and correlations with visual function. Invest Ophthalmol Vis Sci. 2006;47:2080-92.

46. Cooper RF, Dubis AM, Pavaskar A, Rha J, Dubra A, Carroll J. Spatial and temporal variation of rod photoreceptor reflectance in the human retina. Biomed Opt Express. 2011;2:2577-89.

47. Merino D, Duncan JL, Tiruveedhula P, Roorda A. Observation of cone and rod photoreceptors in normal subjects and patients using a new generation adaptive optics scanning laser ophthalmoscope. Biomed Opt Express. 2011;2:2189-201.

48. Takayama K, Ooto S, Hangai M, et al. High-resolution imaging of the retinal nerve fiber layer in normal eyes using adaptive optics scanning laser ophthalmoscopy. PLoS One. 2012;7:e33158.

49. Akagi T, Hangai M, Takayama K, Nonaka A, Ooto S, Yoshimura N. In vivo imaging of lamina cribrosa pores by adaptive optics scanning laser ophthalmoscopy. Invest Ophthalmol Vis Sci. 2012;53:4111-9.

50. Scoles D, Sulai YN, Langlo CS, et al. In vivo imaging of human cone photoreceptor inner segments. Invest Ophthalmol Vis Sci. 2014;55:4244-51.

51. Langlo CS, Patterson EJ, Higgins BP, et al. Residual foveal cone structure in CNGB3-associated achromatopsia. Invest Ophthalmol Vis Sci. 2016;57:3984-95.

52. Flannery JG, Bird AC, Farber DB, Weleber RG, Bok D. A histopathologic study of a choroideremia carrier. Invest Ophthalmol Vis Sci. 1990;31:229-36.

53. Razeen MM, Cooper RF, Langlo CS, et al. Correlating photoreceptor mosaic structure to clinical findings in Stargardt disease. Transl Vis Sci Technol. 2016;5:6.

54. Warren C, Scoles DH, Dubis A, et al. Imaging cone structure in autosomal dominant cone rod dystrophy caused by GUCY2D mutations. Invest Ophthalmol Vis Sci. 2014;55:1102-1102.

55. Liu J, Cukras CA, Tam J. Quantitative analysis of photoreceptor swelling in late-onset retinal degeneration using adaptive optics. Invest Ophthalmol Vis Sci. 2016;57:3168-3168.

56. Morgan JIW, Han GK, Cooper RF, et al. Cone photoreceptor inner and outer segment mosaic abnormalities in choroideremia. Invest Ophthalmol Vis Sci. 2016;57:5112-5112.

57. Sun LW, Johnson RD, Williams V, et al. Multimodal imaging of photoreceptor structure in choroideremia. PLoS One. 2016;11: e0167526.

58. Roorda A. Applications of adaptive optics scanning laser ophthalmoscopy. Optom Vis Sci. 2010;87:260-8.

59. Huang D, Swanson EA, Lin CP, et al. Optical coherence tomography. Science. 1991;254:1178-81.

60. Kocaoglu OP, Turner TL, Liu Z, Miller DT. Adaptive optics optical coherence tomography at $1 \mathrm{MHz}$. Biomed Opt Express. 2014;5:4186-200.

61. Kocaoglu OP, Cense B, Jonnal RS, et al. Imaging retinal nerve fiber bundles using optical coherence tomography with adaptive optics. Vis Res. 2011;51:1835-44.

62. Nadler Z, Wang B, Schuman JS, et al. In vivo three-dimensional characterization of the healthy human lamina cribrosa with 
adaptive optics spectral-domain optical coherence tomography. Invest Ophthalmol Vis Sci. 2014;55:6459-66.

63. Torti C, Povazay B, Hofer B, et al. Adaptive optics optical coherence tomography at 120,000 depth scans/s for non-invasive cellular phenotyping of the living human retina. Opt Express. 2009;17:19382-400.

64. Felberer F, Rechenmacher M, Haindl R, Baumann B, Hitzenberger CK, Pircher M. Imaging of retinal vasculature using adaptive optics SLO/OCT. Biomed Opt Express. 2015;6:1407-18.

65. Acton JH, Greenberg JP, Greenstein VC, et al. Evaluation of multimodal imaging in carriers of $\mathrm{X}$-linked retinitis pigmentosa. Exp Eye Res. 2013;113:41-48.

66. Kalitzeos A, Samra R, Kasilian M, et al. Cellular imaging of the tapetal-like reflex in carriers of RPGR-associated retinopathy. Retina. 2019;39:570-580.

67. Morgan JIW, Chung DC, Nozato K, Maguire AM, Bennett J. Imaging retinal structure in patients and carriers of choroideremia. Invest Ophthalmol Vis Sci. 2012;53:4648-4648.

68. Pyo Park S, Hwan Hong I, Tsang SH, Chang S. Cellular imaging demonstrates genetic mosaicism in heterozygous carriers of an X-linked ciliopathy gene. Eur J Hum Genet. 2013;21:1240-8.

69. Curcio CA, Sloan KR, Kalina RE, Hendrickson AE. Human photoreceptor topography. J Comp Neurol. 1990;292:497-523.

70. Godara P, Dubis AM, Roorda A, Duncan JL, Carroll J. Adaptive optics retinal imaging: emerging clinical applications. Optom Vis Sci. 2010;87:930-41.

71. Marcos S, Werner JS, Burns SA, et al. Vision science and adaptive optics, the state of the field. Vis Res. 2017;132:3-33.

72. Curcio CA, Sloan KR. Packing geometry of human cone photoreceptors: variation with eccentricity and evidence for local anisotropy. Vis Neurosci. 1992;9:169-80.

73. Carroll J, Choi SS, Williams DR. In vivo imaging of the photoreceptor mosaic of a rod monochromat. Vis Res. 2008;48: 2564-8.

74. Doble N, Choi SS, Codona JL, Christou J, Enoch JM, Williams DR. In vivo imaging of the human rod photoreceptor mosaic. Opt Lett. 2011;36:31-3.

75. Dubra A, Sulai Y. Reflective afocal broadband adaptive optics scanning ophthalmoscope. Biomed Opt Express. 2011;2:1757-68.

76. Sredar N, Fagbemi OE, Dubra A. Sub-airy confocal adaptive optics scanning ophthalmoscopy. Transl Vis Sci Technol. 2018;7:17.

77. Carroll J, Neitz M, Wolfing J, Gray D, Neitz J, Williams DR. Different genetic causes of red-green color blindness give rise to different retinal phenotypes as assessed with adaptive optics. Invest Ophthalmol Vis Sci. 2004;45:4341-4341.

78. Duncan JL, Zhang Y, Gandhi J, et al. High-resolution imaging with adaptive optics in patients with inherited retinal degeneration. Invest Ophthalmol Vis Sci. 2007;48:3283-91.

79. Duncan JL, Zhang Y, Roorda A. Adaptive optics imaging of macular photoreceptors reveals differences in patients with retinitis pigmentosa and cone-rod dystrophy. Invest Ophthalmol Vis Sci. 2006;47:5667-5667.

80. Ziccardi L, Giannini D, Lombardo G, et al. Multimodal approach to monitoring and investigating cone structure and function in an inherited macular dystrophy. Am J Ophthalmol. 2015;160:301-12 e306.

81. Rha J, Wagner-Schuman M, Moore AT, et al. Adaptive optics imaging of the cone mosaic in oligocone trichromacy. Invest Ophthalmol Vis Sci. 2010;51:6296-6296.

82. Song H, Chui TY, Zhong Z, Elsner AE, Burns SA. Variation of cone photoreceptor packing density with retinal eccentricity and age. Invest Ophthalmol Vis Sci. 2011;52:7376-84.

83. Dubis AM, Cooper RF, Aboshiha J, et al. Genotype-dependent variability in residual cone structure in achromatopsia: toward developing metrics for assessing cone health. Invest Ophthalmol Vis Sci. 2014;55:7303-11.
84. Litts KM, Cooper RF, Duncan JL, Carroll J. Photoreceptor-based biomarkers in AOSLO retinal imaging. Invest Ophthalmol Vis Sci. 2017;58:BIO255-67.

85. Li KY, Tiruveedhula P, Roorda A. Intersubject variability of foveal cone photoreceptor density in relation to eye length. Invest Ophthalmol Vis Sci. 2010;51:6858-67.

86. Lombardo M, Lombardo G, Schiano Lomoriello D, Ducoli P, Stirpe M, Serrao S. Interocular symmetry of parafoveal photoreceptor cone density distribution. Retina. 2013;33:1640-9.

87. Lombardo M, Serrao S, Ducoli P, Lombardo G. Eccentricity dependent changes of density, spacing and packing arrangement of parafoveal cones. Ophthalmic Physiol Opt. 2013;33:516-26.

88. Wilk MA, Dubis AM, Cooper RF, Summerfelt P, Dubra A, Carroll J. Assessing the spatial relationship between fixation and foveal specializations. Vis Res. 2017;132:53-61.

89. Hirsch J, Miller WH. Does cone positional disorder limit resolution? J Opt Soc Am A. 1987;4:1481-92.

90. Cooper RF, Wilk MA, Tarima S, Carroll J. Evaluating descriptive metrics of the human cone mosaic. Invest Ophthalmol Vis Sci. 2016;57:2992-3001.

91. Garrioch R, Langlo C, Dubis AM, Cooper RF, Dubra A, Carroll J. Repeatability of in vivo parafoveal cone density and spacing measurements. Optom Vis Sci. 2012;89:632-43.

92. Liu BS, Tarima S, Visotcky A, et al. The reliability of parafoveal cone density measurements. Br J Ophthalmol. 2014;98:1126-31.

93. Park SP, Chung JK, Greenstein V, Tsang SH, Chang S. A study of factors affecting the human cone photoreceptor density measured by adaptive optics scanning laser ophthalmoscope. Exp Eye Res. 2013;108:1-9.

94. Tanna P, Kasilian M, Strauss R, et al. Reliability and repeatability of cone density measurements in patients with Stargardt disease and RPGR-associated retinopathy. Invest Ophthalmol Vis Sci. 2017;58:3608-15.

95. Abozaid MA, Langlo CS, Dubis AM, Michaelides M, Tarima S, Carroll J. Reliability and repeatability of cone density measurements in patients with congenital achromatopsia. Adv Exp Med Biol. 2016;854:277-83.

96. Giannini D, Lombardo G, Mariotti L, Devaney N, Serrao S, Lombardo M. Reliability and agreement between metrics of cone spacing in adaptive optics images of the human retinal photoreceptor mosaic. Invest Ophthalmol Vis Sci. 2017;58: 3127-37.

97. Talcott KE, Ratnam K, Sundquist SM, et al. Longitudinal study of cone photoreceptors during retinal degeneration and in response to ciliary neurotrophic factor treatment. Invest Ophthalmol Vis Sci. 2011;52:2219-26.

98. Pallikaris A, Williams DR, Hofer H. The reflectance of single cones in the living human eye. Invest Ophthalmol Vis Sci. 2003;44:4580-92.

99. Jonnal RS, Rha J, Zhang Y, Cense B, Gao W, Miller DT. Functional imaging of single cone photoreceptors using an adaptive optics flood illumination camera. Invest Ophthalmol Vis Sci. 2007;48:1955-1955.

100. Jonnal RS, Rha J, Zhang Y, Cense B, Gao W, Miller DT. In vivo functional imaging of human cone photoreceptors. Opt Express. 2007;15:16141-60.

101. Li YG, Zhang QX, Liu L, Amthor FR, Yao XC. High spatiotemporal resolution imaging of fast intrinsic optical signals activated by retinal flicker stimulation. Opt Express. 2010;18: $7210-8$.

102. Rha J, Schroeder B, Godara P, Carroll J. Variable optical activation of human cone photoreceptors visualized using a short coherence light source. Opt Lett. 2009;34:3782-4.

103. Chen Y, Ratnam K, Sundquist SM, et al. Cone photoreceptor abnormalities correlate with vision loss in patients with Stargardt disease. Invest Ophthalmol Vis Sci. 2011;52:3281-92. 
104. Godara P, Cooper RF, Sergouniotis PI, et al. Assessing retinal structure in complete congenital stationary night blindness and Oguchi disease. Am J Ophthalmol. 2012;154:987-1001 e1001.

105. Pircher M, Kroisamer JS, Felberer F, Sattmann H, Gotzinger E, Hitzenberger CK. Temporal changes of human cone photoreceptors observed in vivo with SLO/OCT. Biomed Opt Express. 2010;2:100-12.

106. Hashimoto H, Kishi S. Shortening of the rod outer segment in Oguchi disease. Graefes Arch Clin Exp Ophthalmol. 2009;247: 1561-3.

107. Bruce KS, Harmening WM, Langston BR, Tuten WS, Roorda A, Sincich LC. Normal perceptual sensitivity arising from weakly reflective cone photoreceptors. Invest Ophthalmol Vis Sci. 2015;56:4431-8.

108. Milam AH, Li ZY, Fariss RN. Histopathology of the human retina in retinitis pigmentosa. Prog Retin Eye Res. 1998;17:175-205.

109. Jonnal RS, Kocaoglu OP, Wang Q, Lee S, Miller DT. Phasesensitive imaging of the outer retina using optical coherence tomography and adaptive optics. Biomed Opt Express. 2012;3:104-24.

110. Litts KM, Messinger JD, Freund KB, Zhang Y, Curcio CA. Inner segment remodeling and mitochondrial translocation in cone photoreceptors in age-related macular degeneration with outer retinal tubulation. Invest Ophthalmol Vis Sci. 2015;56:2243-53.

111. Boulton M, Dayhaw-Barker P. The role of the retinal pigment epithelium: topographical variation and ageing changes. Eye. 2001;15:384-9.

112. Nguyen-Legros J, Hicks D. Renewal of photoreceptor outer segments and their phagocytosis by the retinal pigment epithelium. Int Rev Cytol. 2000;196:245-313.

113. Kellner U, Kellner S, Weber BH, Fiebig B, Weinitz S, Ruether K. Lipofuscin and melanin-related fundus autofluorescence visualize different retinal pigment epithelial alterations in patients with retinitis pigmentosa. Eye (Lond). 2009;23:1349-59.

114. Roorda A, Zhang Y, Duncan JL. High-resolution in vivo imaging of the RPE mosaic in eyes with retinal disease. Invest Ophthalmol Vis Sci. 2007;48:2297-303.

115. Liu Z, Kurokawa K, Kocaoglu OP, Zhang F, Miller DT. Measuring organelle motility in RPE cells in the living human retina. Investig Ophthalmol Vis Sci 2016;57.

116. Liu T, Jung H, Liu J, Droettboom M, Tam J. Noninvasive near infrared autofluorescence imaging of retinal pigment epithelial cells in the human retina using adaptive optics. Biomed Opt Express. 2017;8:4348-60.

117. Lombardo M, Parravano M, Serrao S, Ziccardi L, Giannini D, Lombardo G. Investigation of adaptive optics imaging biomarkers for detecting pathological changes of the cone mosaic in patients with type 1 diabetes mellitus. PLoS One. 2016;11:e0151380.

118. Sohocki MM, Daiger SP, Bowne SJ, et al. Prevalence of mutations causing retinitis pigmentosa and other inherited retinopathies. Hum Mutat. 2001;17:42-51.

119. Bukowska DM, Chew AL, Huynh E, et al. Semi-automated identification of cones in the human retina using circle Hough transform. Biomed Opt Express. 2015;6:4676-93.

120. Lazareva A, Liatsis P, Rauscher FG. Hessian-LoG filtering for enhancement and detection of photoreceptor cells in adaptive optics retinal images. J Opt Soc Am A Opt Image Sci Vis. 2016; 33:84-94.

121. Bergeles C, Dubis AM, Davidson B, et al. Unsupervised identification of cone photoreceptors in non-confocal adaptive optics scanning light ophthalmoscope images. Biomed Opt Express. 2017;8:3081-94.

122. Cunefare D, Langlo CS, Dubra A, Carroll J, Farsiu S. Automatic detection of cones in multi-modal adaptive optics scanning light ophthalmoscope images of achromatopsia. Invest Ophthalmol Vis Sci. 2017;58:300-300.
123. Mariotti L, Devaney N. Performance analysis of cone detection algorithms. J Opt Soc Am A Opt Image Sci Vis. 2015;32: 497-506.

124. Vincent AL, Carroll J, Fishman GA, et al. Retinal structure and function in a pedigree cosegregating achromatopsia and a rhodopsin mutation. Invest Ophthalmol Vis Sci. 2012;53:4591-4591.

125. Dubis AM, Langlo CS, Dubra A, et al. Residual foveal cone structure in CNGB3 achromatopsia: factors for gene therapy candidate selection. Invest Ophthalmol Vis Sci. 2015;56:4264-4264.

126. Ueno S, Nakanishi A, Kominami T, et al. In vivo imaging of a cone mosaic in a patient with achromatopsia associated with a GNAT2 variant. Jpn J Ophthalmol. 2017;61:92-8.

127. Gocho K, Kameya S, Akeo K, et al. High-resolution imaging of patients with Bietti crystalline dystrophy with CYP4V2 mutation. J Ophthalmol. 2014;2014:283603.

128. Greene JB, Ratnam K, Sundquist S, Roorda A, Duncan JL. Cone structure imaged using adaptive optics scanning laser ophthalmoscopy in Bietti crystalline corneoretinal dystrophy. Invest Ophthalmol Vis Sci. 2011;52:4982-4982.

129. Miyata M, Ooto S, Ogino K, et al. Evaluation of photoreceptors in Bietti crystalline dystrophy with CYP4V2 mutations using adaptive optics scanning laser ophthalmoscopy. Am J Ophthalmol. 2016;161:196-205 e191.

130. Carroll J, Dubra A, Gardner JC, et al. The effect of cone opsin mutations on retinal structure and the integrity of the photoreceptor mosaic. Invest Ophthalmol Vis Sci. 2012;53:8006-15.

131. Carroll J, Scoles DH, Langlo CS, et al. Imaging cone structure in patients with OPN1LW and OPN1MW mutations. Invest Ophthalmol Vis Sci. 2014;55:4542-4542.

132. Cideciyan AV, Hufnagel RB, Carroll J, et al. Human cone visual pigment deletions spare sufficient photoreceptors to warrant gene therapy. Hum Gene Ther. 2013;24:993-1006.

133. Patterson EJ, Kasilian M, Kalitzeos A, et al. Assessing cone photoreceptor structure in patients with mutations in the OPN1LW/OPN1MW gene array. Invest Ophthalmol Vis Sci. 2017;58:1257-1257.

134. Patterson EJ, Tee J, Neitz J, et al. Assessing cone mosaic disruption in patients with X-linked cone dysfunction. Invest Ophthalmol Vis Sci. 2015;56:88-88.

135. Patterson EJ, Wilk M, Langlo CS, et al. Cone photoreceptor structure in patients with X-linked cone dysfunction and redgreen color vision deficiency. Invest Ophthalmol Vis Sci. 2016;57:3853-63.

136. Neitz J, Wagner-Schuman M, Dubra A, et al. cone mosaic disruption caused by $\mathrm{L} / \mathrm{M}$ opsin mutations in Bornholm eye disease. Invest Ophthalmol Vis Sci. 2011;52:4896-4896.

137. Day S, Sundquist S, Solovyev A, Zhang Y, Roorda A, Duncan JL. Cone structure in patients with peripherin/RDS mutations. Invest Ophthalmol Vis Sci. 2009;50:999-999.

138. Duncan JL, Talcott KE, Ratnam K, et al. Cone structure in retinal degeneration associated with mutations in the peripherin/RDS gene. Invest Ophthalmol Vis Sci. 2011;52:1557-66.

139. Gocho K, Akeo K, Itoh N, et al. High-resolution adaptive optics retinal image analysis at early stage central areolar choroidal dystrophy with PRPH2 mutation. Ophthalmic Surg Lasers Imaging Retin. 2016;47:1115-26.

140. Wang X, Song H, Folwell M, Latchney L, Chung M. Adaptive optics scanning laser ophthalmoscopy demonstrates reduced foveal cone density in pattern dystrophy. Invest Ophthalmol Vis Sci. 2013;54:1372-1372.

141. Gocho K, Akeo K, Kubota D, et al. High resolution imaging analysis of female carriers and patients of choroideremia with CHM gene mutation. Invest Ophthalmol Vis Sci. 2017;58:307-307.

142. Morgan JI, Han G, Klinman E, et al. High-resolution adaptive optics retinal imaging of cellular structure in choroideremia. Invest Ophthalmol Vis Sci. 2014;55:6381-97. 
143. Rha J, Genead MA, Godara P, et al. High-resolution imaging of photoreceptor structure in choroideremia. Invest Ophthalmol Vis Sci. 2012;53:2120-2120.

144. Sundquist SM, Duncan JL, Zhang Y, et al. Cone structure in patients with mutations in the choroideremia gene. Invest Ophthalmol Vis Sci. 2008;49:2157-2157.

145. Syed R, Sundquist SM, Ratnam K, et al. High-resolution images of retinal structure in patients with choroideremia. Invest Ophthalmol Vis Sci. 2013;54:950-61.

146. Vincent A, Wright T, Garcia-Sanchez Y, et al. Phenotypic characteristics including in vivo cone photoreceptor mosaic in KCNV2-related "cone dystrophy with supernormal rod electroretinogram". Invest Ophthalmol Vis Sci. 2013;54:898-908.

147. Kameya S, Kubota D, Kikuchi S, et al. Whole exome sequencing reveals DFNB31 mutations associated with mild cone-rod dystrophy and sensorineural hearing loss in Japanese family. Invest Ophthalmol Vis Sci. 2017;58:3230-3230.

148. Chung MM, Rossi EA, Song H, et al. In vivo adaptive optics imaging of the cone photoreceptor mosaic in autosomal dominant cone rod dystrophy (AD-CRD) in a three-generation family carrying the I143NT mutation in the guanylate cyclase activator A1A (GUCA1A) gene. Invest Ophthalmol Vis Sci. 2011;52: 5002-5002.

149. Song H, Rossi EA, Stone E, et al. Phenotypic diversity in autosomal-dominant cone-rod dystrophy elucidated by adaptive optics retinal imaging. Br J Ophthalmol. 2018; 102:136-141

150. Kominami A, Ueno S, Kominami T, et al. Case of cone dystrophy with normal fundus appearance associated with biallelic POC1B variants. Ophthalmic Genet. 2018;39:255-62.

151. Godara P, Wagner-Schuman M, Rha J, Connor TB, Jr., Stepien $\mathrm{KE}$, Carroll J. Imaging the photoreceptor mosaic with adaptive optics: beyond counting cones. Adv Exp Med Biol. 2012;723: 451-8.

152. Levison AL, Ratnam K, Roorda A, et al. High resolution retinal images in a family with autosomal dominant retinitis pigmentosa caused by a mutation in NR2E3. Invest Ophthalmol Vis Sci. 2012;53:4587-4587.

153. Park SP, Hong IH, Tsang SH, et al. Disruption of the human cone photoreceptor mosaic from a defect in NR2E3 transcription factor function in young adults. Graefes Arch Clin Exp Ophthalmol. 2013;251:2299-309.

154. Makiyama $\mathrm{Y}$, Ooto $\mathrm{S}$, Hangai $\mathrm{M}$, et al. Cone abnormalities in fundus albipunctatus associated with RDH5 mutations assessed using adaptive optics scanning laser ophthalmoscopy. Am J Ophthalmol. 2014;157:558-70 e551-554.

155. Makiyama Y, Ooto S, Hangai M, et al. High-resolution imaging of the white dot structure observed in fundus albipunctatus. Invest Ophthalmol Vis Sci. 2012;53:5650-5650.

156. Song H, Latchney L, Williams D, Chung M. Fluorescence adaptive optics scanning laser ophthalmoscope for detection of reduced cones and hypoautofluorescent spots in fundus albipunctatus. JAMA Ophthalmol. 2014;132:1099-104.

157. Song H, Williams DR, Latchney L, Dubra A, Chung MM. Fluorescence adaptive optics scanning laser ophthalmoscopy demonstrates intraretinal spots and low cone density in fundus albipunctatus. Invest Ophthalmol Vis Sci. 2012;53: $5675-5675$

158. Klinman E, Maguire A, Han G, Morgan J. Adaptive optics scanning laser ophthalmoscopy and multi-modality clinical imaging in a patient with gyrate atrophy. Invest Ophthalmol Vis Sci. 2013;54:3447-3447.

159. Kameya S, Kabuto T, Kikuchi S, et al. High resolution cone photoreceptor imaging analysis of an occult macular dystrophy patient with RP1L1 mutation. Invest Ophthalmol Vis Sci. 2013;54:3455.
160. Kameya S, Kikuchi S, Gocho K, et al. A cone-rod dystrophy patient with a homozygous RP1L1 mutation. Invest Ophthalmol Vis Sci. 2014;55:3276-3276.

161. Nakanishi A, Ueno S, Kawano K, et al. Pathologic changes of cone photoreceptors in eyes with occult macular dystrophy. Invest Ophthalmol Vis Sci. 2015;56:7243-9.

162. Tojo N, Nakamura T, Ozaki H, Oka M, Oiwake T, Hayashi A. Analysis of macular cone photoreceptors in a case of occult macular dystrophy. Clin Ophthalmol. 2013;7:859-64.

163. Viana KI, Messias A, Siqueira RC, Rodrigues MW, Jorge R. Structure-functional correlation using adaptive optics, OCT, and microperimetry in a case of occult macular dystrophy. Arq Bras Oftalmol. 2017;80:118-21.

164. Baraas RC, Dees EW, Rha J, et al. Cone density and color discrimination in oligocone trichromacy. Invest Ophthalmol Vis Sci. 2011;52:3197-3197.

165. Michaelides M, Rha J, Dees EW, et al. Integrity of the cone photoreceptor mosaic in oligocone trichromacy. Invest Ophthalmol Vis Sci. 2011;52:4757-64.

166. Rha J, Dubis AM, Wagner-Schuman M, et al. Spectral domain optical coherence tomography and adaptive optics: imaging photoreceptor layer morphology to interpret preclinical phenotypes. Adv Exp Med Biol. 2010;664:309-16.

167. Park SP, Lee W, Bae EJ, et al. Early structural anomalies observed by high-resolution imaging in two related cases of autosomal-dominant retinitis pigmentosa. Ophthalmic Surg Lasers Imaging Retin. 2014;45:469-73.

168. Morgan J, Sivalingam M, Han G, et al. Adaptive optics scanning laser ophthalmoscopy and high resolution imaging in autosomal dominant retinitis pigmentosa caused by a novel PRPF31 nonsense mutation. Invest Ophthalmol Vis Sci. 2013;54:3445-3445.

169. Duncan J, Biswas P, Kozak I, et al. Exome analysis identified novel mutations in the FAM161A gene in a family with recessive retinal degeneration. Invest Ophthalmol Vis Sci. 2013;54: 3347-3347.

170. Duncan JL, Biswas P, Kozak I, et al. Ocular phenotype of a family with FAM161A-associated retinal degeneration. Ophthalmic Genet. 2016;37:44-52.

171. Lew YJ, Rinella N, Qin J, et al. High-resolution imaging in male germ cell-associated kinase (MAK)-related retinal degeneration. Am J Ophthalmol. 2018;185:32-42.

172. Duncan JL, Roorda A, Navani M, et al. Identification of a novel mutation in the CDHR1 gene in a family with recessive retinal degeneration. Arch Ophthalmol. 2012;130:1301-8.

173. Dessalces E, Bocquet B, Bourien J, et al. Early-onset foveal involvement in retinitis punctata albescens with mutations in RLBP1. JAMA Ophthalmol. 2013;131:1314-23.

174. Han G, Sulai YNB, Maguire AM, Bennett J, Dubra A, Morgan JIW. Adaptive optics imaging of ABCA4 retinal degeneration. Invest Ophthalmol Vis Sci. 2014;55:2616-2616.

175. Michaelides M, Zakka FR, Aboshiha J, et al. High-resolution imaging in stargardt disease: preliminary observations in preparation for intervention. Invest Ophthalmol Vis Sci. 2014;55:5016-5016.

176. Pang CE, Suqin Y, Sherman J, Freund KB. New insights into Stargardt disease with multimodal imaging. Ophthalmic Surg Lasers Imaging Retin. 2015;46:257-61.

177. Song H, Pugliese A, Rossi E, et al. Adaptive optics scanning laser ophthalmoscopy in stargardt disease reveals decreased cone and rod densities. Invest Ophthalmol Vis Sci. 2013;54:1743-1743.

178. Song H, Rossi EA, Latchney L, et al. Cone and rod loss in Stargardt disease revealed by adaptive optics scanning light ophthalmoscopy. JAMA Ophthalmol. 2015;133:1198-203.

179. Palejwala NV, Gale MJ, Clark RF, Schlechter C, Weleber RG, Pennesi ME. Insights into autosomal dominant Stargardt-like 
macular dystrophy through multimodality diagnostic imaging. Retina. 2016;36:119-30.

180. Baraas RC, Carroll J, Gunther KL, et al. Adaptive optics retinal imaging reveals S-cone dystrophy in tritan color-vision deficiency. J Opt Soc Am A Opt Image Sci Vis. 2007;24:1438-47.

181. Ratnam K, Vastinsalo H, Roorda A, Sankila EM, Duncan JL. Cone structure in patients with usher syndrome type III and mutations in the Clarin 1 gene. JAMA Ophthalmol. 2013;131:67-74.

182. Duncan JL, Sundquist SM, Solovyev A, et al. Cone structure in patients with BEST1 mutations. Invest Ophthalmol Vis Sci. 2010;51:4328-4328.

183. Kay DB, Land ME, Cooper RF, et al. Outer retinal structure in best vitelliform macular dystrophy. JAMA Ophthalmol. 2013; 131:1207-15.

184. Scoles D, Sulai YN, Cooper RF, et al. Photoreceptor inner segment morphology in best vitelliform macular dystrophy. Retina. 2017;37:741-8.

185. Stepien KE, Scoles DH, Sulai YNB, et al. Variability in photoreceptor inner segment morphology in best vitelliform macular dystrophy. Invest Ophthalmol Vis Sci. 2014;55:1590-1590.

186. Ba-Abbad R, Pack A, Aboshiha J, et al. Outer retinal changes associated with the rpgr carrier phenotype: insights from highresolution imaging. Invest Ophthalmol Vis Sci. 2014;55:274-274.
187. Degli Esposti S, Ba-Abbad R, Pack A, et al. High-resolution imaging to probe retinal integrity in RPGR associated rod-cone dystrophy. Invest Ophthalmol Vis Sci. 2014;55:254-254.

188. Akeo K, Kameya S, Gocho K, Kubota D, Yamaki K, Takahashi H. Detailed morphological changes of foveoschisis in patient with X-linked retinoschisis detected by SD-OCT and adaptive optics fundus camera. Case Rep Ophthalmol Med. 2015;2015: 432782.

189. Ambrosio L, Akula JD, Favazza TL, et al. Multimodal imaging analysis of cone photoreceptors mosaic in human juvenile $\mathrm{X}$ linked retinoschisis. Invest Ophthalmol Vis Sci. 2016;57: 2701-2701.

190. Duncan JL, Ratnam K, Birch DG, et al. Abnormal cone structure in foveal schisis cavities in X-linked retinoschisis from mutations in exon 6 of the RS1 gene. Invest Ophthalmol Vis Sci. 2011;52: 9614-23.

191. Duncan JL, Zhang Y, Sundquist SM, et al. Structural correlation using adaptive optics scanning laser ophthalmoscopy in X-linked retinoschisis. Invest Ophthalmol Vis Sci. 2008;49: 5391-5391.

192. Favazza TL, Swanson EA, Ambrosio L, et al. AO-SLO imaging of diseased retina using offset and confocal apertures. Invest Ophthalmol Vis Sci. 2016;57:1662-1662. 